
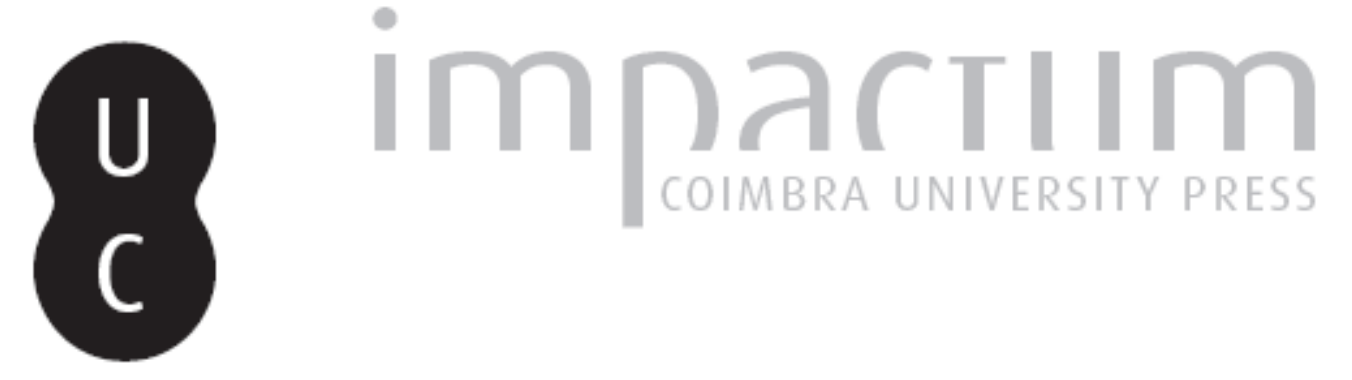

\title{
A Climatologia como componente essencial no diagnóstico e na avaliação dos impactes ambientais em espaços urbanizados: o caso da cidade do Porto
}

\author{
Autor(es): Monteiro, Ana
}

Publicado por: Associação Portuguesa de Riscos, Prevenção e Segurança

URL persistente:

URI:http://hdl.handle.net/10316.2/40188

DOI:

DOI:https://doi.org/10.14195/1647-7723_1_2

Accessed : $\quad$ 26-Apr-2023 15:46:56

A navegação consulta e descarregamento dos títulos inseridos nas Bibliotecas Digitais UC Digitalis, UC Pombalina e UC Impactum, pressupõem a aceitação plena e sem reservas dos Termos e Condições de Uso destas Bibliotecas Digitais, disponíveis em https://digitalis.uc.pt/pt-pt/termos.

Conforme exposto nos referidos Termos e Condições de Uso, o descarregamento de títulos de acesso restrito requer uma licença válida de autorização devendo o utilizador aceder ao(s) documento(s) a partir de um endereço de IP da instituição detentora da supramencionada licença.

Ao utilizador é apenas permitido o descarregamento para uso pessoal, pelo que o emprego do(s) título(s) descarregado(s) para outro fim, designadamente comercial, carece de autorização do respetivo autor ou editor da obra.

Na medida em que todas as obras da UC Digitalis se encontram protegidas pelo Código do Direito de Autor e Direitos Conexos e demais legislação aplicável, toda a cópia, parcial ou total, deste documento, nos casos em que é legalmente admitida, deverá conter ou fazer-se acompanhar por este aviso.

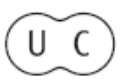




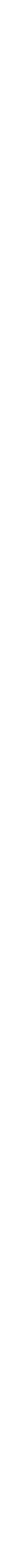




\section{A Climatologia como componente essencial no diagnóstico e na avaliação dos impactes ambientais em espaços urbanizados. O caso da cidade do Porto}

\section{Ana Monteiro *}

\section{Resumo:}

Pretende-se com este trabalho demonstrar que a Climatologia, se direccionar o seu corpo teórico-metodológico para a aplicabilidade dos conceitos, pode revelar-se uma componente indispensável na definição das estratégias de planeamento dos espaços urbanizados. Para tal, recorremos a alguns exemplos extraídos de trabalhos de investigação que desenvolvemos sobre a cidade do Porto e que nos parecem poder ser elucidativos da importância da Climatologia no processo de definiçấo das estratégias de planeamento, nomeadamente, em espaços urbanizados. Palavras chave:

Gestão de espaços urbanizados, impactes ambientais, Geografia Física, Climatologia Urbana, ilha de calor urbano, poluição, saúde.

\section{Résumé:}

La Climatologie comme une composante essentiel pour comprendre et évaluer la magnitude et l' intensité des impactes sur l'environnement dans les aires urbaines - étude de cas à Porto, Portugal.

Avec ce travail on prétend démontrer que, si la Climatologie, concrètement, dirigeait son corps théorique et méthodologique vers l' application des concepts, elle serait une composante indispensable pour la définition des stratégies d'aménagement du territoire. Pour cette conclusion on a fait appel à quelques exemples, avant développés sur la ville de Porto, et qui nous semblent élucidatifs, surtout, pour améliorer la qualité de vie et les conditions de confort des citoyens urbains.

Mots clés:

Aménagement du territoire, impactes dans l'environnement, Géographie Physique, Climatologie Urbaine, îlot de chaleur urbain, pollution, santé.

\footnotetext{
Abstract:

Physical Geography, namely Climatology, can give an useful contribution to understand the complicate network of relation ships among multiple variables responsible for the long list of environmental impacts found in the urban ecosystem.

We support our argument on an example of Oporto, where it is obvious and came out easily, the close links between climate and life quality standards. We show some exemples of how inoperative will be an environmental policy if it tries to solve, for instance, the air and soil quality without knowing in detail the regional and local behavior of temperature, precipitation, pressure, wind, etc.

Key Words:

Land use planning, environmental impacts, Physical Geography, Urban Climatology, urban heat island, air pollution, health.
}

Desde os finais dos anos 80 têm vindoa proliferar amplos e polémicos debates sobre que tipo de oferta de qualidade de vida e bem-estar estará associado às cidades, que justifique a preferência de mais de $40 \%^{1}$ das pessoas do globo e que sustente uma tendência assustadoramente crescente até ao final deste século.

A parentemente, só uma grave perda da noção, por parte do Homem, da sua real dimensão no mundo, pode justificar este tipo de opção contra-natura que, além de agressiva para com os outros elementos do ecossistema, parece sobretudo serfatal para si próprio.

Em Portugal, por exemplo, além das duas grandes

\footnotetext{
* ProfessoraAuxiliar. Institutode Geografia.Faculdade de Letras. Universidade
} do Porto. áreas metropolitanas de Lisboa e Porto, onde se concentra mais de $40 \%$ da população residente do Continente $^{2}$, existem ainda mais cerca de 70 núcleos urbanos de pequena e média dimensão com populações que oscilam entre os 10000 e os 112000 habitantes.

Embora ofluxo de população que sucessivamente se tem vindo a acomodar nas aglomerações urbanas em Portugal tenha diminuido ligeiramente na última década (Fig.1), tal desaceleração no crescimento

1 “...In 1800 only some 50 million people lived in urban areas: by 1985 the number of urban dwellers had risen to 2 billion. In 1800 only $5 \%$ of the world's population were urban dwellers, now the proportion has risen to more than $40 \%$, and by the year 2010 more people will live in towns and cities than in countryside..." (G. LeAN, D. HINRICHSEN, A. Markham, 1990,p.21).

2 INE, Recenseamento Geral da População-1991, Lisboa, 1991. 
populacional não significou, de per si, uma melhor adequação dos equipamentos e das infra-estruturas às necessidades dos residentes e utilizadores das cidades. Muito pelo contrário, esta quebra no ritmo de crescimento da população urbana, traduziu-se, na maior parte dos casos, pelo necrosamento de áreas outrora plenas de vitalidade, que foram progressivamente deixadas ao abandono tanto pela população como pelos agentes económicos.

Em Portugal, à semelhança do que aconteceu noutros países, as aglomerações urbanas foram, ao longo dos últimos anos, perdendo progressivamente vantagens comparativas, enveredando por processos de degenerescência e degradação devido sobretudo ao abandono dos principais agentes económicos. Deixaram de ser espaços economicamente vantajosos para oinvestimento produtivo e perderam, por completo, a capacidade atractiva para a função residencial (Fig.1).

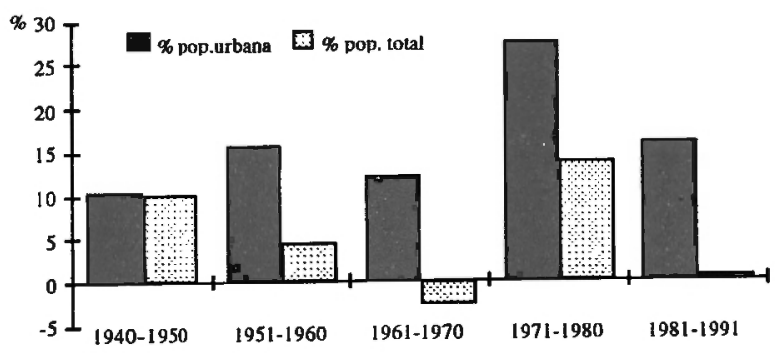

Fig. 1 - Variação da população total e urbana em Portugal entre 1940 e 1991 (T. S algueiro, 1992).

A fuga para a periferia da cidade, suportada pelo menor custo dos transportes e pelo novo quadro de acessibilidades, gerou um grande desinteresse e uma diminuição dos laços de dependência entre os cidadãos, as actividades económicas e o espaço urbano.

Todavia, a especialização flexível, encorajadora de empreendimentos independentes mas interligados, capazes dereagir rapidamente às mudanças do mercado, implícita nos novos modelos de desenvolvimento económico, parece indiciar que as aglomerações urbanas poderão vir a ser, mais uma vez, a forma de organizaçãodo espaço a privilegiar num futuro próximo (A. Lipietz, 1992; J. Ferrão, 1991; M. Castells, 1990; etc.).

Se a concorrência deixar de assentarnas condições de produçãoe passar a existir em funçãodacriatividade e da flexibilidade dos sistemas de produção, como parece começar já a suceder, e a competição passar a ocorrer ao nível dos projectos e dos laboratórios, então, tornar-se-á necessária uma maior proximidade entre os centros de investigação, a indústria e os serviços de apoio.
Assim, o "modo de organização territorial de sucesso" (J. FERRÃo, 1991), onde se possam concentrar as actividades produtivas, os laboratórios, os centros de pesquisa, que facilite a difusão das inovações e intensifique as sinergias necessárias ao novo modelo económico, parece poder vir, portanto, a reavivar a atractividade potencial do tecido urbano.

Contudo, para se adequar a este novo papel, o meio urbano tem de oferecer, para além da facilidade de comunicação e de um excelente quadro de acessibilidades, um enquadramento físico atractivo para uma população que será agora muito mais exigente em termos de qualidade de vida.

A necessidade de sedução, através da qualidade do meio ambiente, passará a ser, para as novas aglomerações urbanas, tão importante como as suas capacidades de oferta em redes de comunicação, diversidade funcional, etc.

Os novos espaçoș de crescimento desenvolverse-ão consoante a sua capacidade de integrar, harmoniosamente, um aparelho sócio-produtivo muito mais exigente nos padrões de bem-estar e qualidade de vida ${ }^{3}$.

A Comissão das Comunidades Europeias, no Livro Verde sobre o Meio Ambiente Urbano (1991), enumerou já um vasto conjunto de causas profundas da degradação urbana (C.C.E., 1991, p.40-45) na Europa e definiu um conjunto de orientações, instrumentos de acção e prioridades para uma estratégia comunitária do ambiente urbano (C.C.E., 1991, p.4880) a que Portugal não poderá ficar alheio.

Face ao tipo de problemas e às principais causas de degradação do meio ambiente, em diversas cidades europeias, a Comunidade Europeia definiuum conjunto de orientações-chave para melhorar a qualidade do ambiente urbano, das quais salientamos: coordenação-integração do desenvolvimento económico e da política social, responsabilização do indivíduo, da empresa e da administração pública, pelos impactes causados no ambiente e sustentabilidade ambiental e económica (C.C.E., 1991, p.53-54).

É precisamente neste último item quea Geografia Física poderá dar um importante contributo. Com efeito, está particularmente apta a colaborar tanto no diagnóstico, como na avaliação e mitigação dos inúmeros impactes ambientais herdados da aplicação das anteriores políticas de crescimento económico.

A Geografia Física possui instrumentos teórico-

\footnotetext{
${ }^{3}$ Esta inversăo na valorizaçăo da qualidade ambiental dos meios urbanos é notória até nas técnicas de marketing dos agentes imobiliários. Tanto os novosempreendimentos para fins residenciais, como as grandes superficies multifuncionais em construçãona área do Portorevelam,já, a necessidade de vender uma imagem, que se traduz até pelo nome que é dado aos empreendimentos eque incluemuma forte ligaçãoadiversas componentes ambientais, incluindo normalmente no seu nome "Jardim", "Quinta", Lago", etc.
} 
metodológicos eficazes para ajudar a cuidar da estrutura física da cidade, ao nível do planeamento, dos transportes urbanos e da protecção e valorização das áreas naturais e do património histórico.

Claroque umaabordagem geográfica das questões ambientais, ao envolver preocupações com os lugares e o meio envolvente, implica uma renovação da noção de espaço e obriga ao convívio próximo entre as apreciações objectivas e subjectivas, bem como à necessidade de síntese entre a Geografia humana e fisica. O que, podendo contribuir para fortalecer a sua importância, enquanto disciplina autónoma e original, não evitará o inevitável debate em torno das questões epistemológicas que motiva.

Propomo-nos contribuir para este debate sobre o papel da geografia no diagnóstico e na avaliação dos impactes ambientais em espaços urbanizados recorrendo ao exemplo das relações de dependência emergentes entre Clima-Poluição Atmosférica e, por exemplo, o nível do conforto, a saúde e o bemestar dos cidadãos urbanos que demonstrámos em anteriores trabalhos (A. MoNTEIRO, 1993).

O diagnóstico da totalidade das pressões sobre o suporte ambiental que o fenómeno urbano portuense tem vindoa exercer, nomeadamente no clima regional e local, obrigou-nos a tentar perceber o subsistema climático em vez de, mais uma vez, tentar arrumálo num qualquer grupo de uma das muitas tipologias de classificação disponíveis.

A clarificação e a comprovação experimental das relações de causalidade existentes entre o Clima e o tipo de fenómeno urbano (A. MonTEIro, 1993), nomeadamente através da forma e da intensidade da "ilha de calor" (Fig.2), poderá facilitar a rendição dos mais optimistas e dos que subscrevem uma visão demasiado antropocêntrica do nosso papel, como parte integrante do Ecossistema, à validade da ideia que tipos de organização espaço-funcional, como por exemplo o da cidade do Porto, representam o vértice de uma enorme pirâmide de ilusões de superioridade doHomem sobre o seu suporte ambiental, da qual nada beneficiaremos.

Não restam dúvidas que a complexa geometria das superfícies urbanizadas, a forma e orientação

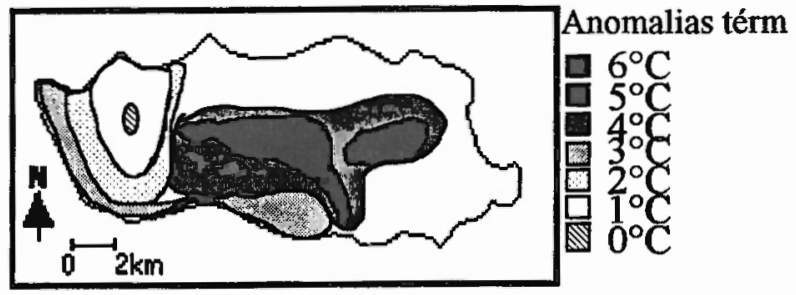

Fig.2 - Anomalias térmicas médias resultantes de um conjunto de mediçőes itinerantes de temperatura efectuadas na cidade do Porto entre 1988 e 1992. dos edifícios, as propriedades térmicas dos diversos materiais utilizados, a impermeabilização do solo ou o calor libertado pelas diversas actividades antrópicas, contribuem consideravelmente para alteraro balanço energético nas cidades (Fig.2).

A grande aglomeração de pessoas, a profusão de actividades produtivas, a constante necessidade de trocar, o mais eficazmente possível, bens, serviços e informações, faz com que nos meios urbanos ressalte, com redobrada importância, um segundo fluxo de circulação de energia - artificial - que se associa ao fluxo natural, com origem na radiação solar, tornando a compreensão do subsistema climático urbano consideravelmente mais complexa.

$O$ balanço energético, que para o meio urbano poderá ser definido por $\mathbf{Q} \mathbf{s}+\mathbf{Q} \mathbf{f}+\mathbf{Q} \mathbf{i}=\mathbf{Q} \mathbf{l}+\mathbf{Q g}+\mathbf{Q} \mathbf{e}^{4}$ (I. DoUGLAS, 1983, p.40), varia de cidade para cidade, consoante a morfologia da área, a volumetria do espaço construído, a cor e os materiais de construção dos edifícios, o tipo de pavimento das ruas. A dimensão da cidade, em termos de população, o tipo de tecido industrial e a fluidez de circulação do tráfego interferem, também, no resultado final desta equação.

Assim, a grande complexidade dos processos de resolução no interior do Sistema Climático e a enorme variabilidade intrínseca, ao nível das respostas, que o caracteriza, impedem que, na maioria das vezes, se consigam evidenciar, com clareza, e de forma mais ou menos expedita, as causas que geram os efeitos que se pretendem compreender e minimizar quando se tem por objectivo ajudar a definir as estratégias de ordenamento dos espaços urbanizados.

As inúmeras dificuldades em dissociar a variabilidade intrínseca ao Sistema Climático da variabilidade induzida pelas acções antrópicas, associadas ao receio instalado na comunidade científica em emitir juízos de valor sobre umaáreade investigação onde os processos são tão complexos e em grande parte ainda desconhecidos, têm contribuído decisivamente para mascarar a gravidade dos impactes provocados pela urbanização no Ecossistema em que seinclui, nomeadamente, ao nível das modificações físico-químicas do seu envólucro gasoso.

As consequências imediatas das várias intervenções no circuito energético natural e do extraordinário incremento nas fontes de alimentação de um circuito energéticointeiramente artificial, têm vindo, no entanto, a facilitar a identificação dos riscos tornando-os perceptíveis à escala de uma ou duas gerações.

A compreensão do tipo e da magnitude dos impactes que este tipo de modificações no espaço

\footnotetext{
$\overline{4}$ Sendo Qs-energiaradianterecebida dosol, Qf-energiageradaporcombustão, metabolismo e energia dissipada nos processos industriais, Qi-calor emitido pelo interior da Terra, Q1- perda de calor por evaporaçăo, Qgperda de calor por condução no solo, nos edifícios e nas ruas, Qe- perda de calor por irradiaçăo.
} 
exerce ao nível da saúde e do bem-estar dos cidadãos urbanos, se comprovada e percebida, poderá motivar os decisores e os diversos actores intervenientes no tecido urbano a repensar o mosaico funcional de modo a satisfazeros padrões de bem-estare qualidade de vida actuais.

A demonstração deste tipo de relação de causalidade pode conseguir-se recorrendo a alguns exemplos mais ou menos óbvios dos quais começamos por destacar, por nos parecer particularmente estimulante como chamada de atenção sobre a precaridade do equilíbrio do ecossistema urbano, o agravamento de determinadas patologias do foro respiratório associadas à modificação do comportamento de alguns elementos climáticos e à degradação da qualidade do ar provocadas pelo metabolismo urbano.

Embora as ligações entre Poluição Atmosférica, Clima e Saúde, no que se refere, por exemplo ao agravamento de algumas patologias doforo respiratório, só sejam detectáveis com um trabalho interdisciplinar mais prolongado e sólido, gostaríamos de recordar, a título meramente exemplificativo, que foi possível, no caso da cidade do Porto, demonstrar que ao longo dos últimos anos emergiram consistentes e notórias coincidências entre a intensidade da ilha de calor urbano, aépoca do ano com maiores concentrações de $\mathrm{SO}_{2}$ e fumos negros e o aumento do número de crianças com menos de 10 anos que recorreram à urgência de um dos hospitais centrais portuenses, por agravamento da doença (A. MonTEIRO, 1993, p.367-375).

A análise do comportamento de alguns elementos climáticos, nos dias em que ocorreram os internamentos, efectuada através dos registos diários da estação de Porto-Serra do Pilar, revelou uma forte relação entre a temperatura e a insolação relativa e o número de crises de asma desencadeadas nas crianças com menos de 10 anos (Quadro I).

Tanto as crises de asma, como as crises de bronquite, desenvolveram-se e agravaram-se nas crianças

Quadro I - Comportamento da temperatura nos dias em que houve internamentos de "adultos" ( $>10)$ e crianças $(<10)$ com bronquite, asma e DPCO no Hospital de S.João-Porto, entre 1 de Abril de 1989 e 31 de Março de 1991.

\begin{tabular}{|c|c|c|c|c|c|c|c|}
\hline & & $\begin{array}{c}\mathrm{N}^{\circ} \\
\text { DIAS }\end{array}$ & MÉDIA & MÍNIMO & MÁXIMO & MODA & C.VARIAÇÃO \\
\hline \multirow{6}{*}{$\begin{array}{l}\text { TEMP. } \\
\text { MEDIA }\end{array}$} & ABR.89/MAR91 & 730 & 15,1 & 3,8 & 28,7 & & 31,8 \\
\hline & SÓ DIAS C/BRONQ $(>10)$ & 79 & 14,2 & $\underline{6,6}$ & 28 & 16,3 & 22,6 \\
\hline & SÓ DIAS C/ASMA (>10) & 171 & 14,6 & 3,9 & $\underline{29,7}$ & 18,1 & 33,7 \\
\hline & SÓ DIAS C/DPCO $(>10)$ & 280 & 13,6 & 4,6 & 26,9 & 16,4 & 35,5 \\
\hline & SÓ DIAS C/ASMA (_10) & 494 & 15,4 & 3,8 & $\underline{29,7}$ & 20,2 & 30 \\
\hline & SÓ DIAS C/BRONQ (_10) & 96 & 15,5 & 3,8 & 24,1 & 18,9 & 29,7 \\
\hline \multirow{6}{*}{$\begin{array}{l}\text { TEMP. } \\
\text { MINIMA }\end{array}$} & ABR.89/MAR91 & 730 & 11,3 & $-0,5$ & 24,1 & & 40,6 \\
\hline & SÓ DIAS C/BRONQ (>10) & 79 & 10,6 & 2 & 20,4 & 15 & 42,5 \\
\hline & SÓ DIAS C/ASMA (>10) & 171 & 11,3 & $\underline{0,4}$ & $\underline{24,1}$ & 11,4 & 42 \\
\hline & SÓ DIAS C/DPCO (>10) & 280 & 9,8 & 0,1 & 21,5 & & 48,1 \\
\hline & SÓ DIAS C/ASMA (_10) & 494 & $\underline{11,5}$ & 0,1 & 21,6 & 14 & 37,9 \\
\hline & SÓ DIAS C/BRONQ (_10) & 96 & 12 & 0,4 & 19,6 & & 36,2 \\
\hline \multirow{6}{*}{$\begin{array}{l}\text { TEMP. } \\
\text { MÁXMMA }\end{array}$} & ABR.89/MAR91 & 730 & 19,6 & 8 & 37,7 & 14 & 28,7 \\
\hline & SÓ DIAS C/BRONQ $(>10)$ & 79 & 18,6 & $\underline{10,4}$ & 34,1 & & 29,6 \\
\hline & SÓ DIAS C/ASMA (>10) & 171 & 18,9 & 8 & $\underline{37,7}$ & & 31,2 \\
\hline & SÓ DIAS C/DPCO $(>10)$ & 280 & 18 & 8,6 & 35,8 & 14 & 30 \\
\hline & SÓ DIAS C/ASMA ( 10$)$ & 494 & $\underline{19,9}$ & 8,6 & 37,4 & 14 & 27,5 \\
\hline & SÓ DIAS C/BRONQ (_10) & 96 & 20 & 8 & 32,6 & 23,1 & 26,8 \\
\hline
\end{tabular}


nos dias com temperatura média, temperatura mínima e temperatura máxima mais elevada do que a média da totalidade do período (Quadro I).

Se a maioria dos 494 casos de asma e dos 96 casos de bronquite ocorreram nos meses que correspondem à época mais fria do ano, não seria de esperar que a média das temperaturas desse período superasse a média da totalidade do período.

Compreende-se sim, se, como fizemos, confirmarmos que o maior número de casos ocorreu em dias com temperaturas ligeiramente acima damédia mensal.

Embora os efeitos reais das alterações provocadas pelo meio urbano na saúde dos seus habitantes, possam ser, facilmente, confundidos com as maiores e mais profundas diferenças sócio-económicas, que este tipo de regiões normalmente alberga, não deixa de ser evidente que a inadequação arquitectónica dos edifícios para residência ou para local de trabalho, 0 maior ruído, o aumento do uso de iluminação artificial, a maior concentração de pessoas e a poluição atmosférica, que caracterizam qualquer meio urbano, concorrem certamente com outros factores de índole fisiológica, para agravar um variadíssimo conjunto de patologias (A. MonTEIro, 1990, p.33-49).

No caso da região portuense para além das fortes anomalias térmicas positivas já mencionadas (Fig.2), assistiu-se a um extraordinário aumento da temperatura no final da década de 80 e no início dos anos 90. Aumento, que é excepcional à escala da série secular, sobretudo evidente nas temperaturas máximas e mínimas.

A par destas manifestações de mudança climática regional verificou-se o incremento do número de dias com $\mathrm{SO}_{2}$ acima dos $100 \mu \mathrm{g} / \mathrm{m}^{3}, 150 \mu \mathrm{g} / \mathrm{m}^{3}$ e 200 $\mu \mathrm{g} / \mathrm{m}^{3}$ (Fig.3), nos postos localizados no interior da

$N^{\circ}$ de ocorrências

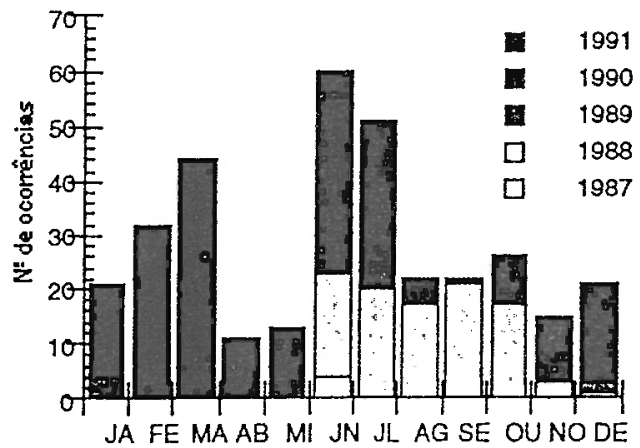

Fig. 3 - Número de dias com $\mathrm{SO}_{2}$ acima de $150 \mu \mathrm{g} / \mathrm{m}^{3}$ nos postos da rede de avaliação da qualidade do ar da DGQA/Porto, localizados dentro ou próximo dos limites do concelho do Porto, entre 1 de Abril de 1987 e 31 Março de 1991 (A. MonteIRo, 1993). cidade e o aumento no número de veículos e no congestionamento dos fluxos de circulação nesta região(Fig.4).

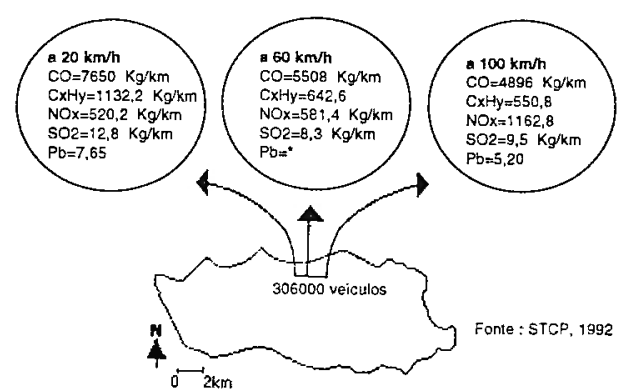

Fig.4 - Emissões prováveis para a atmosfera consoante a velociđade de circulação do número total de veículos que circulam diariamente no perímetro urbano portuense ${ }^{5}$ (A. MoNTEIRo, 1993).

Só os 306000 veículos que diariamente circulam na cidade doPorto são responsáveis, comojá referimos, pela libertação para a atmosfera $\mathrm{de}^{6}: 5508 \mathrm{~kg} / \mathrm{km}$ de monóxido de carbono, $643 \mathrm{~kg} / \mathrm{km}$ de hidrocarbonetos, $581 \mathrm{~kg} / \mathrm{km}$ de $6 x i d o s$ de azoto, $8 \mathrm{~kg} / \mathrm{km}$ de dióxido de enxofre e entre 5 a $7 \mathrm{~kg} / \mathrm{km}$ de chumbo (Fig.4). Valores que quase duplicam se a fluidez da circulação diminuir.

As emissões poluentes dos veículos nas horas de maior congestionamento de tráfego ultrapassam os $7650 \mathrm{~kg} / \mathrm{km}$ de monóxido de carbono, os $1132 \mathrm{~kg}$ / $\mathrm{km}$ de hidrocarbonetos, os $520 \mathrm{~kg} / \mathrm{km}$ de óxidos de azoto, os $13 \mathrm{~kg} / \mathrm{km}$ de dióxido de enxofre e os $7 \mathrm{~kg} /$ $\mathrm{km}$ de chumbo, previstos para uma velocidade média de circulação de $20 \mathrm{~km} / \mathrm{h}$. As ruas estreitas, a topografia acidentada e a pouca dispersão de um grande número de actividades funcionais urbanas, contribuem para impedir que, a determinadas horas do dia, a velocidade média dos veículos seja sequer de $20 \mathrm{~km} / \mathrm{h}$.

A contaminação dos solos pelo chumbo demonstrou, claramente, que alguns dos efluentes libertados pelos veículos, se depositam e/ou reagem quimicamente com a atmosfera, a pouca distância do lugar de emissão (A. MonTEIRo, 1993, p.352).

Assim sendo, não nos parece difícil deduzir, para a região portuense, que a degradação da qualidade do ar e as modificações no padrão tếrmico regional geradas pelo metabolismo urbano podem ser co-

\footnotetext{
5 Ocálculo das emissões foi elaborado de acordo com as tabelas sugeridas pelo Handbook of Emission Factors, non-industrial sources, Ministry of Health and Environmental Protection, The Hague, 1980, p.64-65.

6 Infelizmente não existe na J.A.E., nos S.T.C.P., nem na C.M.P. informação sobre a quilometragem efectuada, em média, por cada veículo, dentro da cidade. Por este facto, ficamos impedidos de avaliar o real e efectivo contributo do tráfego para a modificação da composição química da atmosfera portuense. Os valores que referimos traduzem apenas as emissôes poluentes geradas por cada quilómetro percorrido dentro da cidade.
} 
responsáveis, por exemplo, pelo aumento do número de crises asmáticas e brônquicas ocorridas em crianças residentes na área do Porto e as modificações.

A inclusão, desde início, no processo de planeamento urbano, da componente climatológica teria evidenciado as inúmeras modificações climatológicas introduzidas, nesta área, pela intensificação do processo de urbanização, demonstrando, provavelmente, que algumas das opções, por exemplo, ao nível da definição da rede viária, não surtirão os efeitos desejados de requalificação da vida urbana, nem contribuirão para melhorar as condições de saúde, conforto e bem-estar dos cidadãos residentes e/ou utilizadores do espaço urbano portuense.

Tendo em consideração o aumento das temperaturas verificado no núcleo central da cidade e a frequênciacom que se ultrapassaram os limitesmáximos admissíveis de alguns poluentes por toda a cidade, surgiriam naturalmente, aos decisores, outras prioridades, talvez mais simplese muito mais eficazes.

A definição da localização dos espaços verdesé um óptimo exemplo de como, sem se descurar a sua importante função lúdica como espaços de recreio e lazer, quando correctamente planeados, podem também contribuir para diminuir o ruído e filtrar alguns poluentes ou ainda incrementar a ventilaçãoe modificar os sistemas de circulaçãonacidade, reduzindo, portanto, as temperaturas extremas.

Faltou, no entanto, durante a fase de diagnóstico do Plano Geral de Urbanização da cidade do Porto, o conhecimento dos diversos padrões térmicos urbanos e das interrelações existentes entre a intensidade da "ilha de calor urbano", a conductividade calórica e a capacidade de armazenamento de energia de determinados materiais de construção, etc. Teria sido 6bvia para os decisores a necessidade de condicionar, para além das volumetrias, os materiais de construção e as cores das fachadas, em determinadas áreas da cidade.

A ponderação sobre as acções prioritárias em termos de ordenamento do território com o objectivo de o requalificar teria sido claramente diferente se o grupo de trabalho tivesse tomado conhecimento que nem a diferenciação topográfica $E-W$, nem a presença próxima de dois importantes mosaicos de água (o mar e o rio Douro), nem, tão pouco, as repercussões em termos de diversidade de ocupação do espaço, inerentes aos seus mais de oito séculos de história, são suficientes para dissimularos impactes do metabolismo urbano portuense ao nível do balanço energético, geradores de diferenças máximas entre a temperatura na cidade e na periferia da ordem dos $6.9^{\circ} \mathrm{C}$, ou para diluir e atenuar os efeitos da quantidade de efluentes emitidos para a atmosfera na degradação da qualidade do ar e dos solos da região.

\section{BIBLIOGRAFIA}

Câmara Municipal do Porto, Plano Geral de Urbanização. Porto, 1983.

Casterls, Manuel, "Estrategias de desarrollo metropolitano en las grandes ciudades españolas : la articulacion entre crecimiento econ6mico y calidad de vida". Las grandes ciudades en la decada de los noventa, BORJA, JORDI et al. (ed.), Editorial Sistema, Madrid, 1990, p.17-64.

C.C.E., Livro Verde sobre o Ambiente Urbano. Direcção-Geral do Ambiente, Segurança Nuclear e Protecçశ̊o Civil, Bruxelas, 1991.

Douglas, 1., The urban environment. Edward Arnold, London, 1983.

FERRåo, J., “Terciarização e território: emergência de novas configuraçð̃es espaciais?" Análise Social, vol. XXVI, 114, 1991, p.829-845.

Lean, Geoffrey; Hinrichsen, D; Markham, A., Atlas of the environment. WWF, Arrow Books, London, 1990.

LIPIETZ, A.; LeBorgne, D., "Idées fausses et questions ouvertes de l'après-fordisme", Espace et Sociétés, Editions L'Harmattan, Paris, 1992, p.39-68.

Ministry of Health and Environmental Protection, Handbook of Emission Factors. Non-Industrial Sources. The Hague, 1980.

MonTEIRo, A.M.R., “'O Porto e os portuenses no final do séc.XX ou as relaçชes entre os homens e um ecossistema urbano em entropia acelerada". Revista da Faculdade de Letras, Geo. grafia, I Série, vol.VI, Universidade do Porto, 1990, p.5-64.

MONTEIRO, A.M.R., O clima urbano do Porio- contribuição para a definiçāo das estratégias de planeamento eordenamento do território. FLUP, Porto, 1993, 436 p., polic..

Salgueiro, Teresa, A cidade em Portugal - uma geog rafia urbana Ediçốes Afrontamento, Porto, 1992. 